\title{
Complicated narratives of "Korean-ness": Towards strategic provisionality in parental involvement
}

\author{
Seungho Moon \\ Loyola University Chicago, smoon3@luc.edu \\ Jeesun Jung \\ Ohio University - Main Campus
}

Follow this and additional works at: https://ecommons.luc.edu/education_facpubs

Part of the Education Commons

\section{Author Manuscript}

This is a pre-publication author manuscript of the final, published article.

\section{Recommended Citation}

Moon, Seungho and Jung, Jeesun. Complicated narratives of "Korean-ness": Towards strategic provisionality in parental involvement. Race Ethnicity and Education, 21, 5: 643-660, 2018. Retrieved from Loyola eCommons, Education: School of Education Faculty Publications and Other Works, http://dx.doi.org/10.1080/13613324.2017.1294567

This Article is brought to you for free and open access by the Faculty Publications and Other Works by Department at Loyola eCommons. It has been accepted for inclusion in Education: School of Education Faculty Publications and Other Works by an authorized administrator of Loyola eCommons. For more information, please contact ecommons@luc.edu.

\section{(c) $($ () $\ominus$}

This work is licensed under a Creative Commons Attribution-Noncommercial-No Derivative Works 3.0 License. (c) Informa UK Ltd trading as Taylor and Francis Group, 2017. 


\title{
Complicated narratives of "Korean-ness":
}

\section{Towards strategic provisionality in parental involvement}

\author{
Abstract \\ The purpose of this paper is to advance the discourse on parental involvement drawing from \\ Butlerian notion of strategic provisionality. In developing a new approach to understanding \\ cultural differences and their relation to Korean parental involvement, the authors analyze \\ qualitative and quantitative data from five New York metropolitan elementary schools. The \\ authors examine the ways in which "Korean-ness" and Korean parental involvement are \\ discursively constructed and embodied in sociopolitical and historical contexts in the United \\ States. We present two themes related to Korean parental involvement: (a) the double-edged \\ component of respect for teachers and (b) biopolitics related to English language and parental \\ involvement. By challenging normalized understanding about Korean-ness, the authors suggest \\ a different approach to ethnoepistemology in order to enrich discourses concerning parental \\ involvement and ethnic/racial studies. \\ Keywords: parental involvement, Korean parents, biopolitics, strategic provisionality

\section{Introduction} \\ A decade ago, Race, Ethnicity, and Education published a special issue addressing the \\ current state of research on Asian American and Pacific Islanders (AAPI) and its implications. In \\ his introduction to the issue, Coloma coins the term "disorienting" for the process of "negating, \\ interrupting, and contesting" normalized knowledge in understanding AAPI (Coloma 2006, 2). \\ He called for a new paradigm for recognizing the complexity of racial/ethnic identities among \\ AAPI. More recently, Ng, Lee, and Park (2011) have critically reviewed Asian American \\ educational literature and urged the development of new directions for research on Asian
}


American communities that will more aptly demonstrate the complexity of Asian-ness in education. The purpose of this paper is to participate in such discussions on AAPI identities while disorienting a normalized explication of Korean culture or "Korean-ness." In the creation of a new approach to complicating cultural "differences," the authors revisit issues on Korean parental involvement drawing from Butler's (1993) notion of strategic provisionality — that is, an individual's constant refusal to be fixed and confined within a ready-made subject. This paper examines the ways in which "Korean-ness" is discursively constructed, and thus "Korean" parental involvement is politically embodied in a specific sociocultural and historical context in the United States (US). We explore the possibility of rethinking the White/Korean bifurcation by presenting local narratives of Korean parents residing in the New York metropolitan area. Predominant discourses about Korean culture and identity ironically reproduce and even perpetuate monolithic, hegemonic narratives in describing cultural "differences" in terms of the collective self and other. This epistemology and methodological practice limits opportunities for imagining multiple versions of "Korean-ness" and implementing diverse parental involvement strategies. Thus, more in-depth historical, cultural and political analyses of Korean culture could lead to more informed conversations on cultural differences at personal, educational, and academic levels, and could open spaces for recognizing diverse approaches to parental involvement (Moon 2011a).

Highly influenced by critical race theory (CRT), the mainstream literature on parental involvement indicates the consensus that a culturally responsive school-parent partnership provides "the best [educational] opportunity to thrive in school" (Lazar and Slostad 1999, 206). This approach to parent-teacher collaboration ultimately helps all students, specifically students of color, by providing them with a better educational environment (Souto-Manning 2006). 
Grounded in these traditional studies, literature on Korean parent involvement also has attempted to make the voices of Korean parents heard in order to increase awareness and sensitivity about Korean culture (Lee 2005; Lim 2012; Sohn and Wang 2006). The authors in this study recognize the value of categorizing cultural sameness/difference in parental involvement as explicated in CRT. Yet, we challenge possible problems that can emerge if racial/ethnic identities are universalized and generate normalized versions of understanding those racial/ethnic identities. Theoretically informed by strategic provisionality (Butler 1993), this paper investigates multiple narratives of Korean families as a means to articulate a discursive practice of parental involvement.

Two major research questions are raised and discussed: (a) In what ways does a different theoretical lens inform the conceptualization of a racial/ethnic identity manifested through "Korean" parental involvement? (b) What other discourses are possible when cultural differences are reviewed via strategic provisionality? Two distinct themes answer these questions: (a) the myth of "respecting teachers" as constituting a barrier for parental involvement; and (b) the harmful application of biopolitics in teacher-parent interactions and decision-making processes. We borrow the Foucauldian (1977) notion of biopolitics, namely a mechanism in which disciplinary power operates through normalizing judgment about the population and generating self-surveillance. In conclusion, we offer a frame to reconsider Korean-ness, discursively constructed within a very specific sociopolitical context.

\section{Backgrounds of the research: Beyond critical Asian theory and critical model minority}

\section{theory}

Understanding the self and the other has been a major issue in race/ethnicity studies. This has been pursued in order to "minimize" cultural gaps between "mainstream" and the 
"marginalized" groups. In the US context, revisiting Eurocentric educational practices, including parental involvement, is the presupposed foundation of advancing literature in the field. Predominant literature advocates for culturally sensitive parent-teacher collaboration so that authentic understanding of cultural difference ultimately supports "minority" students by providing an adequate and relevant educational environment (Liebkind, Jasinskaja-Lahti and Solheim 2004; Souto-Manning 2006). Multicultural educators emphasize that children from diverse backgrounds can receive "the best opportunity to thrive in school" (Lazar and Slostad 1999, 206), only if schools and parents work collaboratively by considering culturally responsive educational practices.

Grounded in literature supporting culturally relevant parental involvement for culturally and racially marginalized groups, extant studies offer insights into Korean parents' educational experiences and obstacles to their involvement in schools (e.g. Bang 2009; Lim 2012; Lee 2005; Sohn and Wang 2005). Lee (2005) used a case study to investigate the process of parent participation in a Korean English Immersion Program from kindergarten to fourth grade in a public school. The study demonstrated that Korean parents experienced difficulties in participation due to structural and cultural barriers inherent in schools, including the lack of English proficiency, time, and social etiquette/manners. Drawing from in-depth interview data, Sohn and Wang (2006) explored immigrant Korean mothers' views on parental involvement in US schools, and articulated the mothers' difficulties stemmed from differences in language and culture. Lim's case study on the Korean American parent and school partnership revealed that the parents utilized collectivistic networking within their ethnic communities to overcome their challenges and became actively engaged in schools. Despite this involvement, Asian parents were often seen as academic-oriented and "non-participating" (Lim 2012, 99). 
Informed by empirical research supporting the benefit of culturally responsive parental involvement, researchers have used critical race theory (CRT) and critical Asian model minority theory (CAMMT) in order to articulate cultural differences between White teachers and Korean parents. Critical Asian theory (CAT) is the extension of CRT, distinguishing Asians' unique cultural elements from other racial groups. Chang (1993) refers to Asian American legal scholarship in order to theorize different ways of thinking among Asian Americans. As indicated by his book title Asia as method, Chen (2010) utilizes Asian epistemology in order to represent lived, cultural experiences when explicating common cultural elements among Asian communities.

As part of CAT discourse, much of the literature presents counter narratives to challenge the myth of model minority theory. CAMMT has been circulated to describe multiple versions of experiences among Asian youth and families beyond the model minority myth. This theory challenges the label of "a model race" in the US in terms of Asian communities-namely that they typify "hard work, diligence, and docility" (Chae 2004, 61). Literature on Asian families and youth dismantle the myth of model minority and challenge its hegemonic practice. The label of model minority underpins the pervasive belief and policy that no Asian student or parent require extra support from schools (Kim and Yeh 2002). For instance, Chae (2004) explores the educational and socio-economic experiences of working class Korean youth in New York City public schools and critically describes narratives of working class Korean-origin youth. At-risk Korean youth encounter stereotypical images regarding their identity, inhibiting their actual learning opportunities. Chae's study argues for rethinking stereotypical representations of Asian students in order to challenge "hegemonic ways of thinking about identity and culture that perpetuate the model minority" (Chae, 2004, 70). 
This paper utilizes the Butlerian notion of "strategic provisionality" in order to minimize challenges embedded within CAT and CAMMT. Counter narratives about Asian communities ironically reproduce deficit ideology among the communities, in contrast to the desired endeavor of destabilizing the Eurocentric hegemony, and reporting their urgent needs (Poon, Squire, Kodama, Byrd, et al. 2015). By using the logic of "exclusion through inclusion" (Palacios 2014, 5) embedded in model minority theory, counter narratives still encounter dilemmas of reinforcing the inclusion/exclusion binary in reporting complicated stories among Asian Americans. In other words, CAMMT discourse provides counter narratives that reaffirm "normal" and "right" norms coined by Eurocentric hegemony. These counter narratives still adopt the norms framed by Eurocentric ideologies by unintentionally "subtracting" Asian-ness by assimilating individuals into White norms (Valenzuela, 1999). Due to this ironic state of affairs, Poon et al. (2015) suggest avoiding the universalized term "Asian" in indicating the research participants' identity among AAPI as well as using a more detailed theoretical framework going beyond CAMMT to enrich the conversation. Framed by the Butlerian (1993) notion of strategic provisionality, we situate current challenges of Korean families in the US within historical, cultural, and political contexts. Our central issue encompasses the ways in which the nexus of power operates within the Korean communities by reproducing a set of social norms.

\section{Problematizing one "Korean-ness" and strategic provisionality ${ }^{1}$}

Hall (1997) articulated that race is a floating signifier rather than a fixed biological element. By accepting Hall's theoretical stance, the authors agree that racial and ethnic identity

\footnotetext{
${ }^{1}$ This section on Butler's strategic provisionality, with a major revision, appears in Moon's (2011a) unpublished dissertation study (pp. 252-255).
} 
cannot be essentialized within one version of "Korean-ness." Stacey Lee (2006), for example, explicates several complexities existing within racial identities such as class, generation, and gender. Theoretically, we adopt Butler's (1993) notion of strategic provisionality to articulate a problematic label of Korean parents in this paper. Strategic provisionality, according to Butler, is the constant rejection of a ready-made subject. Butler's (1999) theory of performativity rejects the assumption that a subject voluntarily acts outside of discourses. Rather, the subject is never permanent nor stable, yet is provisional. Even the identity of particular "marginalized" groups has no constant element.

Butler's strategic provisionality is inspired by Spivak's (1998) strategic essentialism. A false signifier of "women" is politically used, despite the fact that the signifier of women cannot be fully expressed. Butler recognizes this political dilemma of using a false signifier tactically for social change. Yet, Butler argues against this notion of strategic essentialism in that the instrumental use of identity normalizes "we-ness," mainly concentrating on collective, essentialized elements of identity. Additionally, strategic essentialism sustains the volitional actions of the subject, leading to an assumption that cultural groups control the use of identity label at "will," outside of discourse before the actual interaction between self and others. The political use of identity generates a set of normalized, regulatory mandates, despite its "good" purpose of promoting social transformation. Butler problematizes this instrumental usage of identity, despite its specific purpose for political action. Butler states, “...the identity-sign I use now has its purposes [and] seems right, but there is no way to predict or control the political uses to which that sign will be put into the future. And perhaps this is a kind of openness, regardless of its risks, that ought to be safeguarded for political reasons" (Butler 1993, 311). A fixed notion of identity already presupposes exclusions of people who do not follow a set of social norms 
assigned to the cultural group of "women," "Korean," or "people of color." By emphasizing the permanent openness of identity, Butler constantly challenges regulatory imperatives of identity and allows questioning of the signifier of identity. She argues for preserving the signifier of identity label as "a site of rearticulation" and always keeping open the possibility of future political signifiers $(1993,312)$.

We subscribe to Butler's concern regarding the essentialized understanding of Korean culture. Thus, the authors revisit "Korean” parental involvement, informed by Butler's (1993) strategic provisionality—discursive constructions in motion —within the specific sociopolitical and economic context. Explaining Korean-ness using a collective "we" may become an instrument for reinstituting the hegemonic ideology of patriarchy, classism, heterosexism, and ableism to oppress "other" people within the Korean community. Without critical investigation of "Korean" identity, a monolithic version of "Korean-ness" may perpetuate a set of social norms, representing middle-class, patriarchal, and heterosexual values. Reflecting on this theoretical and practical issue, this inquiry explores other possible avenues to discourse when strategic provisionality is applied to reviewing "Korean" culture.

\section{The study: Method and data sources}

The current study is part of a larger study (Kwon, Suh, Bang, Jung, \& Moon, 2010) that examined the cultural gap that exists between US teachers and Korean families in their perceptions of educational goals, school satisfaction, and beliefs and practices concerning parental involvement. We revisited and reexamined the same qualitative data yet with a different theoretical stance, particularly framed by poststructuralist theories. This study attempted to advance inroads into the subject supported by extant literature on Korean parental involvement. Jackson and Mazzei argue for "plugging one text into another"-namely, valuing thinking with 
theories about the same qualitative research data framed by multiple theoretical perspectives (Jackson and Mazzei 2013, 261). Examining qualitative data across multiple perspectives is important, powerful in that diverse theoretical frameworks create new questions and enable researchers to revisit the existing findings from manifold angles (Jackson and Mazzei 2013). By fully subscribing to Jackson and Mazzei's emphasis on thinking with theories, we aimed to imagine new questions and implications about "Korean" parental involvement, guided by the multiplicities of "Korean-ness" as well as its discursive construction within a specific sociopolitical context.

In a larger study, Kwon et al. (2010) applied a mixed-method research approach with the use of surveys and in-depth interviews. The researchers intentionally selected public schools in the New York metropolitan areas. These were five elementary schools where Korean students comprised more than $20 \%$ of the total population. Among the 430 Korean parents who submitted the survey, $62.6 \%$ were immigrants, $9.4 \%$ came to the US to study themselves, $6.4 \%$ migrated in order for their children to study in US schools, and 12.6\% came to the US for business purposes. At the time of data collection in 2006-2008, the annual net income varied from $22.5 \%$ who earned under $35 \mathrm{~K}, 40.9 \%$ who earned from $35 \mathrm{~K}$ to $65 \mathrm{k}$, and $36.6 \%$ who made above $65 \mathrm{~K}$. The years that the parents lived in the United States varied greatly: 5.5\% had resided in the United States for 3 years while $41.4 \%$ had resided in the United States for more than 10 years. At the end of the survey, we provided an open-ended questionnaire allowing parents to share their opinions. Out of the five elementary schools, 143 teachers participated in the survey, and 89.4\% of the teachers indicated their race/ethnicity as White. On the survey, all of the participants were asked to voluntarily indicate their interest for follow-up interviews. Based on these responses, we contacted the teachers, the administrators, and the parents. The participants were purposefully 
selected to represent a diverse group. The semi-structured interview questions were developed based on the survey findings. Individual interviews with four teachers, four administrators, and eight Korean parents lasted for about one hour each, and all interview data was transcribed.

Informed by critical race theory, our previous research has focused on analyzing the cultural gaps between Korean parents and US teachers. By examining cultural differences, our previous project supported the findings of the existing literature on Korean families and their school involvement (Bang 2009; Lim 2012; Lee 2005; Sohn and Wang 2005). Notably, we provided educational suggestions in order to narrow the cultural gaps between Korean families and US teachers. We requested US teachers to reflect on teaching practices critically as well as to promote equity by implementing culturally responsive practices (Kwon et al. 2010). A critical theory version of introducing "Korean" culture and Korean parental involvement was urgent for the five authors when we analyzed and published the larger study. We believed that making the voices heard from the marginalized group was integral for equity-oriented pedagogy.

The leading author of this paper, however, was highly influenced by poststructuralist theories and challenged a monolithic version of "Korean-ness" supported by critical race theory. The authors of this study initiated conversations to investigate "Korean-ness" differently by drawing from Butler's theory of strategic provisionality. Patterns from the interview data were re-coded and re-generated (Glaser and Strauss 1999). Major themes include the parents' perception and satisfaction on (a) curriculum and practices of English as a Second Language (ESL); (b) relationships and communication with teachers; and (c) fair treatment for children and parents. These themes were revisited with a poststructuralist version of qualitative inquiry in order to interpret multiple, conflicting voices within the data. While revisiting the codes, we noticed multiple layered accounts embodied within teacher professionalism and authority issues. 
Furthermore, a different theoretical framework provided multiple angles in analyzing sensitive issues related to ESL programs and possible unfair treatment of Korean children and their parents. In the following findings section, we articulate complicated local narratives in regards to these two issues: (a) teacher authority and (b) biopolitics in parental involvement.

\section{Multiplicity of cultural "differences"}

Empowerment or enabling the voice of an "oppressed" racial/ethnic group is one of a school's ethical and pedagogical responsibilities (Cummins 2009; Delgado-Gaitan 1991). The predominant literature on culturally responsive education calls for White teachers to be critical of their own racial and ethnic subjectivities (Sleeter 2008). While interviewing and analyzing both survey and interview data from a different theoretical lens, we notice that Korean parents presented multiple narratives in explaining their perceived and actual barriers to active schoolhome collaboration. Local narratives are introduced to articulate Korean parental involvement since we argue that no universalized version of Korean parental involvement exists. The notion of strategic provisionality is applied in problematizing a universalized understanding of Koreanness.

\section{The trap of teacher authority: Respect and fear}

Researchers primarily describe East Asian identity by referring to Confucianism, specifically its hierarchical teacher-student or teacher-parent relationship (De Bary 1998; Yum 2000). Conventional narratives include the premise that Asian parents trust teachers' professionalism and do not actively share different ideas during the decision making process. Our inquiry questions if these assumptions are valid. What are the potential problems if teachers apply such grand, conventional narratives to understanding and practicing a "desirable" teacher-Korean parent relationship? We 
addresses the complexity of Korean identity by providing multiple sets of narratives. Informed by Butler's strategic provisionality, we explore another approach to understanding “Korean-ness.”

Research on Korean parents similarly reveals that they defer professional judgment to teachers and rarely challenge teachers' authority (Lee and Manning 2001). According to traditional Confucianism, the teacher is a role model of benevolence, and in return, students and their parents should offer total respect to teachers. The idiom "never even step on a teacher's shadow" illustrates the respect paid to the teacher within Confucianism. This philosophy seems to be embodied among Korean parents when evaluating teacher performance as well as their interactions with teachers. In the survey data, more than half of the Korean participants (69.4\%) reported that they were always ready to listen to the teachers and the school. Almost one third of the parents $(73.3 \%)$ believed that they should listen to and follow teachers' professional judgment. For example, in her interview below, Gurie, a Korean mother, supported such stereotypical images of Korean parents:

If your kids get into trouble at school, you would ask them first about why and what happened ... But, most Korean parents scold their children, "You deserved the punishment at the school" then [the parents] go to their teachers and apologize for their children's behaviors.

Gurie's statement corresponds with the survey data that Korean parents rely heavily on teachers' judgment rather than listening carefully to children's complaints concerning teachers' possible unfair treatment. Korean parents carry the burden of challenging and addressing possibly unfair treatment of their children, regardless of teachers' stereotypes. While analyzing the stereotypical narrative of Korean parents' perception of teacher professionalism, it is necessary to create a new conversation devoted to rethinking the double-bind of teacher authority and professionalism. Multiple local, contradictory narratives exist in reviewing the notion of respecting teachers: 
Gia: I want to bring the issue [of unfair treatment] to the principal and the teachers. But I am worried that it might work against my child.

Hanna: I am not complaining to [teachers and the school] — not because I am satisfied with the school, but because I don't want to cause any conflict with the school. Honestly, I dare not say to them that there is discrimination.

Unlike Gurie's interview excerpt, Gia's narrative offered a new lens to review the discourse about the practice of respecting teachers. Gia was more cautious about provoking possible discrimination against her child due to reporting a problem to the school authority. She wanted to avoid immediate conflict by looking at the bigger picture of successfully maintaining a year-long relationship with the teacher. Similarly to Gia, Hanna shared her major concerns about publicly revealing a challenging issue. Hanna did not speak out about her child's unfair treatment, not because of "respecting" the teacher or being satisfied with the school, but because of possible negative consequences that could impact her child. As a strategy for conflict management, Hanna took the position of not standing out, fearing that her child could become a target for punishment.

In expressing how teacher authority could relate to possible unfair treatment for their children, Gia and Hanna verbalized the ways in which teacher criticism can be a double-edged sword for Korean parents. The traumatic, negative experiences that Korean parents recall with authority in Korea opens up a new perspective for rethinking the teacher-parent relationship. Lee (2005) presents an interview excerpt from Korean parents who expressed the trauma of being verbally abused by teachers in their native country. One mother shared her memories of a teacher who, whenever a conflict arose, used abusive language to justify a child's misbehavior by attributing his or her low socio-economic status (SES) or being raised by a single parent as the reasoning for his or her behavior. During a focus group interview, this parent reported, "When a student challenged a teacher... [the teachers would say], 
'You have no father'... and that would be the most humiliating thing that anyone could say to a child...We don't challenge authority, or at least, we used to not do so, our generation" (Lee $2005,305)$. Due to past experience with a more authoritative teacher system in Korea, Korean parents are not accustomed to this new set of social norms, where parents are regarded as collaborators in the decision-making process and resolve conflicts together with teachers.

In the survey data the authors collected, administrators and teachers verbalized their willingness to listen to parents' opinions carefully. Ana, an assistant principal said, “...the more we know about you, the more we know that there is an interest and a willingness to do something. The parents should make themselves known to the teacher by periodic conversations, also to the administration of the school." The authors agree with Ana's emphasis on holding conversations regularly in order to exchange different opinions. However, the message of "we are willing to listen to you" should be reviewed in light of the high-risk challenges of the teacher-parent relationship, particularly related to teacher authority. Such traumatic prior experiences with teachers generates a challenging dynamic in sharing conflicting opinions, specifically those containing negative feedback.

We noticed that administrators and teachers ignored the fraught perspective on teacher respect held by Korean parents. During her interview, Maya, a superintendent, reported her satisfaction with Korean parents by utilizing this stereotypical image of respecting teachers. She commented, "I find Korean parents to be very respectful. So in terms of feeling comfortable [sic] to communicate, I'm very comfortable communicating with them in many cases, more-so than the non-Korean parents, who are less respectful, in my opinion." Without a careful examination of local narratives, this stereotypical image does not actually help to support Korean parents' needs, since politeness and non-assertiveness are misinterpreted as an assent. 
The narrative of "respecting teachers" embraces the double-phenomena of respect and fear related to teacher authority. The respect for teachers involved not only relying on teachers' professionalism, but also on dealing with the fear of challenging teachers' authority. Many parents were afraid that their claims of unfair treatment might cause more disadvantage to their children. Without recognizing this power/knowledge operation (Foucault 1980) in schools, Korean parents do not appreciate the school personnel's message of "I'm here to listen to your opinion" or "I find Korean parents are respectful" when they are deciding what to share and what to withhold. This rhetoric of respecting teachers operates as a set of regularity norms when Korean parents interact with their teachers in the US. A universalized narrative regarding the teacher-parent relationship, particularly framed by Neo-Confucian ideals, normalizes and reproduces hierarchical expectations of what course parents should follow when interacting with their children's teachers. By the same token, teachers and administrators apply this monolithic version of Korean identity in practicing "proper" educational support both for students and their parents. In articulating the notion of strategic provisionality, Butler (1999) problematizes contemporary cultural politics. Collective identity perpetuates normalizing expectations for "proper" actions, and thus narrowing down a person's identity within exclusive, collective norms. Teachers who expect Korean parents to show respect to them, mainly driven by their stereotypical expectations of Koreans, may make negative judgments or ostracize Korean parents who do not follow such expectations (Moon, 2011b). Maya, the superintendent in this study, may be confused about Korean parents if the parents do not follow a set of social norms, such as respecting teachers' authority, but instead aggressively interact with teachers regarding possible unfair treatment towards their children.

Butler (1993) emphasizes the openness of identity that is constantly constructed by particular discourses within a sociopolitical, historical, and cultural context. She proposes strategic provisionality 
in order to rethink the current identity politics ostracizing the marginalized group (e.g., LGBT) within marginalized groups (e.g., women) by preserving a collective identity constrained within a patriarchal, heterosexual normalcy. Just as no one version of "woman" exists, neither does a single Korean identity. Korean identity cannot be reduced to elements of Neo-Confucianism, such as showing respect to teachers' professionalism. As Gia and Hanna expressed their feelings of not sharing their complaints with teachers, Korean parents' identity is not predictable, yet is discursively constructed depending on the sociocultural context of the actual interaction. A set of cultural norms, such as the strict NeoConfucian understanding of the teacher-student/parent relationship, prohibits Korean parents from taking an active role in decision-making and being assertive in requesting services for their children. Reflecting on Butler's (1999) performativity theory, it is not the Korean who performs Korean identity with free will. Rather, a set of social norms in "Korean" culture constructs the ways in which Koreanness discursively operates within the sociopolitical context (Moon 2011b). A political application of collective identity is crucial in understanding strategic provisionality. The next section is explicitly related to the ways in which strategic provisionality can be applied to considering the complexity of Korean-ness.

\section{Biopolitics and strategic provisionality of "Korean-ness"}

"Korean" parental involvement is complicated by many interwoven factors such as issues of generation, gender, citizenship, class, language, and more. By embodying the multiplicity of Korean parents' experience, this section explicates the ways in which "Korean" culture is contested by self-surveillance and follows a set of social norms. Most notably, we investigate how the Foucauldian (1977) notion of biopolitics operates not only as a self-control mechanism among Korean parents while interacting with teachers in the US, but it also acts as another "normalizing" process to treat "Koreans" as a universalized concept. Perpetual foreigner 
syndrome reproduces and operates the self-other dichotomy by normalizing Koreans as the Other. The meaning of "Korean-ness" is analyzed using the frame of strategic provisionality in order to recognize the multiplicity of Korean identity.

As the extant literature supports, a language barrier is a crucial issue that hinders active parental involvement (McClelland and Chen 1997; Turney and Kao 2009). Most notably, the lack of English proficiency limits active participation in contributing to new school policies (Koh, Shin, and Reeves 2014). The authors recognize the power of English, which operates as cultural, social, and symbolic capital (Bourdieu and Passeron 1977/2015). English enables Korean parents to fully engage in social interactions with "all" parents, not only during meetings with school personnel, but also during daily interactions with other parents. In spite of its long US immigration history, the Asian American community constantly struggles with perpetual foreigner syndrome - that is, the social practice of considering Asians as foreigners, not active US citizens, thus creating another instance of "civic ostracism" (Kim 1999 as cited in Ng et al. 2007). Consequently, Asian Americans are perceived as strangers instead of US citizens, and such behavior is endured and internalized by Asian American themselves (Ng et al. 2007). Microaggressions towards Asian Americans portray this syndrome, evident in phrases such as "Where are you 'originally’ from?" "You speak English so well!” (Wu 2001). This perpetual foreigner syndrome is technically interlocked with biopolitics (Foucault 1976), harmfully preventing Korean children and their parents from pursuing equal educational opportunities by "policing" their behaviors against the standard of Eurocentric norms.

Foucault (1997) defines biopolitics as a mechanism combining an individual body with politics. Politically, "abnormality" (e.g., Korean-ness) creates self-surveillance in order to be treated as "normal" by following Eurocentric norms. Sovereign power controls bodies through 
legal enforcement, punishment, and other top-down strategies. Disciplinary power, on the other hand, operates through normalizing judgment processes and generates self-surveillance. The subject is normalized and controlled not by the law, but by self-control and disciplines. The "Othering" process engenders the bifurcation of normal and abnormal when setting up expectations about what Korean parents can and cannot do. Korean children and parents themselves sustain the culture of self-control through this normalized practice (Moon 2011b).

Biopolitics is directly interwoven with perpetual foreigner syndrome projected onto Korean communities. It creates the disciplinary mechanism to control the subject and to monitor the ways in which Korean parents speak and interact with others. Biopolitics can generate the myth that English language services exclusively promote engaged parental involvement. This misleading assumption about educational guidance mainly focuses on linguistic issues, and thus disregards cultural elements that actually limit active parental involvement. Furthermore, biopolitics perpetuates another hegemonic practice in parental involvement by characterizing Korean identity as unified as well as by preserving perpetual_foreigner narratives. In the survey and interviews, administrators and teachers communicated a priority of providing multilingual services in order to enhance parental involvement. They consider this linguistic service as a strategy when developing active school-family collaboration. During an interview, Lisa, a principal, emphasized that her school was sensitive about linguistic issues among Korean parents and felt confident about the school's multi-lingual policy of sending out communication materials to each student's home. She said, "We do have several teachers who speak Korean here... We also have been striving more and more to put anything in writing [communication materials] in Korean as well as Spanish and English naturally. So we strive...we push to have that done more and more... We're very sensitive to [the language issue]." According to Lisa, 
this school provides newsletters or communication materials in multiple languages, including Korean, endeavoring to promote efficient communication between Korean parents and schools. During the interview, interviewers had a follow-up question for Lisa, asking if the school actively advertises an official translation service at school for Korean parents. She responded, "Well, I don't know if they [Korean parents] actually know that. I think that they know that we do have Korean teachers because everyone seems to know Mrs. Kang [an ESL teacher with Korean heritage]. Everyone knows Mrs. Kang. I don't know if it's [spread] by word of mouth. But if they do come in we will let them know [concerning the translation service] ... we're very sensitive to that." Unlike her expressed intention to promote efficient discourse between Korean parents and school personnel concerning parental involvement, Lisa's school did not actively introduce this translation service to Korean parents.

During the interview, Lisa constantly highlighted her school's ongoing linguistic support for Korean parents by stating, "We do the best as we can to accommodate when necessary... I do think that people feel kind of intimidated not knowing the predominant language." She continuously underscored that "[Korean parents] hesitate a little bit because of the language... They need better communication.” Lisa attributed Korean’s lack of parental involvement to linguistic barriers in schools and concentrated on providing multilingual communication services in order to promote parental involvement. A linguistic element is crucial in considering the barriers and strategies for promoting parental involvement. However, applying the perpetual foreigner syndrome to Koreans disallows proper educational support by ignoring cultural divisions that constitute much larger elements than linguistic barriers. Most notably, Sook, a second-generation immigrant, elaborated on the difficulty of sharing her "different" educational perspective with teachers during our interview. 
Sook concentrated on cultural divisions between her child and teachers. Sook shared her concerns regarding possible discriminations against her child, not because of actual linguistic barriers, but because of a bias towards Asian American communities. She stated, "I think I would have no problem [in communicating] with the school [in English] since I grew up here... But I experienced conflicts with the teachers and it was hard to change their perceptions of us." Sook started to address her struggles by describing conflicts with teachers as not just a linguistic issue, but also as representing a cultural dissonance between herself and the school. During the interview, Sook continued, "I always worried if my child is discriminated at school because of black eyes and black hair. My mother was racially discriminated against in Maryland when she immigrated to the US in 1973. My child, Soyong, seems to think that she is just an 'American.' I am concerned that my child will suffer from racial discrimination by not considering her different skin color from others...[US] teachers form a bias towards Asian children, either favorable or unfavorable, they typically assume that Asian children and their parents do not speak English. So, I intentionally write a welcoming card to teachers and indicate that I do not have any difficulty in communicating in English.”

Sook was worried about a possible racial discrimination being applied to her and her child due to possessing a different body image from that of the White norm. She addressed the multiple layers of pressure legitimated by biopolitics; US teachers establish "low" expectations about her child and herself due to her "Asian" body. For instance, Sook can speak fluent English, yet her "Korean-body" operated as the subject in applying stereotypical images about Asians. Her daughter, Soyong, did not consider herself as a Korean immigrant, identifying herself as simply being "American." Soyong did not seem to share Sook's fears concerning discriminations applied to her grandmother, mother, and, supposedly, herself. In Sook's case, sending children 
to ESL classes was an urgent issue incorporated into educational practices founded upon a bias. Whether or not a child is fluent in English, perpetual foreigner syndrome influences teachers while conducting ESL programs and labels students as English Language Learners (ELLs). Sook expressed a high level of concern in respect to the ESL program: "If you are a Korean, the school would recommend you to take ESL even if you are good at English.” Korean parents were sensitive about ESL classes, particularly those whose children are born and raised in the US. They worried that ESL classes would limit their children's equal learning opportunities and integration into the "mainstream" culture in classrooms. Olivos pointed out that structural inequalities within schools, such as grouping and tracking via ESL classes, limited the equal learning opportunities for students of color, although such decision is ostensibly out of "good intentions" (Olivos 2006, 50).

Despite Sook's effort to make her voice heard, teachers and administrators have not demonstrated sufficient effort to interpret cultural "differences," instead attributing cultural barriers to English language difficulties. Sook's attempt to "speak" is not properly heard by teachers and administrators. In her work Can the subaltern speak? Spivak (1988) argues that the subaltern cannot speak. The subaltern's voice is rarely heard due to the hegemonic, colonial agenda from dominant patriarchal, Eurocentric ideologies. Even if it is heard, the dominant group's sociopolitical interests fabricate the voice of the subaltern. Spivak presents the paradox of saving brown women from brown men through the colonial power of White men as shown in the sati-a widow sacrifice in India. Not hearing the brown woman's voice, brown men create the myth that a widow voluntarily participates in the sati (Kim, Moon, and Joo 2013). As a woman unable to speak in a patriarchal hegemonic culture, Sook expressed frustration that teachers and administrators did not hear her voice due to the complexity of cultural barriers hindering parental involvement. 
Thus, biopolitics is involved in communication between teachers and Korean parents, and precludes teachers' deeper level of understanding about Korean parents and their school involvement. No single, collective racial/ethnic experience exists (Lee, 2006). Cultural “differences” are not universal, yet are complex as described in the rhetoric of respecting teachers and the intersectionality of race/ethnicity, immigration history, and gender in constructing "Koreanness." Despite the complexity of Korean identity, normalized educational practices in schools have become a mechanism of self-control, in which Korean students and their parents discipline themselves through self-regulation by putting effort into adding the Eurocentric school norms (Foucault 1977). This normalized practice produces both self-control as well as an "unwelcoming" atmosphere in schools as Korean parents experience it (Bang 2009, 129). Korean parents feel a disconnection from school or being ostracized from the cultural norms at school. $\mathrm{Ng}$ et al. (2007) strongly argue that dismantling teachers' preconceptions of Asian-ness with the use of foreign-ness is a major leap. This leap challenges the Othering discourse, which considers all Korean parents from the perpetual foreigner frame - a frame that should be reframed.

A "unified" cultural group such as Korean or Korean American does not exist. The notions of Korean-ness should be situated within a sociopolitical, historical, and cultural context, not reduced to "perpetual foreigner syndrome" or biopolitics imposed onto the Korean community. In her book, Other Asias, Spivak (2008) discusses that singularizing the notion of Asia limits the subjectivities within a specific geographical location and a specific skin color. It is important to pluralize the complex notions of Asian-ness. Like Spivak (2008) states:

"Asia" is not a place, yet the name is laden with history and cultural politics. It cannot produce a naturalized homogeneous "identity" ... It can ... serve to set limits to mere identitarianism in any one of the politico-geographical entities. (p. 9) 
By underscoring the complex notions of Asia, Spivak invites exploration of cultural identity without restricting oneself within the geographically, physically, and ideologically limited notions of Asia. Influenced by Spivak (2008), we problematize the current discourse in US education that "Korean" is forcefully connected with a monolithic culture confined in biopolitics and perpetual foreigner syndrome. Such an educational perspective neglects counter-narratives about complex notions of Korean-ness, while attempting to consider "one" racial group identity as Korean or Asian American. Any endeavor to use collective "we-ness" to identify who I am and who they are always fails (Butler, 2005). Efforts to explain "Korean-ness" for a political reason is inevitable, as the supporters of identity politics argue. Requesting adequate multilingual services for a Korean community is imperative, promoting culturally relevant practices. Although the label of "Korean" is politically driven, collective identity generates problems by excluding counter narratives, as shown in Sook's interviews.

Strategic provisionality offers a new frame for political actions, minimizing a normalized, collective understanding of "Korean" culture. In fighting for proper political supports, strategic provisionality emphasizes a temporality in defining what and who the term "Korean" indicates. The assumptions about the two "different" cultures between Korean parents and US teachers are provisional. Collective Korean-ness is tentatively used in order to challenge the populational reasoning of dividing us [Korean parents] and them [US teachers], yet the provisionality of identity still allows for the recognition of the multiplicity of Korean identities. Moreover, strategic provisionality leaves open a political space by not ostracizing the marginalized people within the community. For instance, Koreans, as a political group, request more English classes for "Korean" children who desperately need more linguistic services. By the same token, this collective "Korean-ness" is always provisional in that other people's different needs in the 
Korean community should be recognized. Thus, the sign of "Korean" is not predictable for future political use and always is open to different usages of this collective term (Butler 1993).

\section{Discussion: Beyond the One "Korean-ness" in parental involvement}

Making the voices of Korean parents heard has been important to equity and justice work in the parental involvement discourse. Researchers have provided multiple narratives in order to challenge a Eurocentric, middle class version of parental involvement. These studies debunk a deficit model of parental involvement by providing different narratives of other parents with different sociocultural assets and narratives. We do not disagree with the effort to create a space where Korean parents and their children's teachers can openly discuss issues and find ways to benefit all children (Cummins 2009; Delgado-Gaitan 1991). Nor do we underestimate the effort to include diverse narratives in order to challenge a deficit model $—$ one that is regarded as passive school involvement from parents of color. Rather, responding to the request of incorporating a new paradigm for examining racial/ethnic identities among AAPI (Coloma 2006), we suggest a different framework for considering racial/ethnic studies: that is, challenging existing "norms" for parental involvement based on a historical, cultural analysis of Korean-ness.

\section{Beyond the collective Asian-ness}

The use of Pan-Asianism or the concept of "one" Korean-ness seems to be indispensable in the fight against Eurocentric educational practices. Influenced by poststructuralist theories, research on Asian cultural identity continuously revisits the impossibility of using a collective category of “Asian-ness" (Kumashiro 2006; Lee 2006). This practice, grounded in collective solidarity, ignores the multiple interpretations of experiences, while standardizing "differences." A politics of identity rejects a passive reception of already defined, stable notions of Korean-ness or White teachers, failing to note sociocultural constructions of identities and difference. 
Considering the implications of linguistic and embodied enactments of cultural difference is vital (Miller 2005). The notion of strategic provisionality offers a frame for rethinking the potential dangers of group "solidarity" and explicate discursively constructed notions of identities and culture.

In articulating identity and culture, Foucault (1980) uses the notion of power/knowledge as the ways in which the subject is constituted by discursive and non-discursive practices. Discourse encompasses both linguistic signs and systematic practices of constructing realities and truths with the use of words, signs, and symbols. Power/knowledge that thus resides in discourse and power is operated through discourses in multiple directions, not as a top-down hierarchy. Influenced by Foucault, Jabal and Riviere (2007), discourses indeed constitute social realities, the meanings of cultural sameness/difference, and cultural diversity. Power/knowledge is exercised in determining who says what, and how it is said, and in what circumstances (Moon 2011a). For example, the notions of Korean culture and the "cultural gap" that exists between Korean parents and their teachers are all constituted within particular discourses. Current predominant discourses on Korean-ness or Korean parent involvement are founded upon the binaries of White/people of color, and emphasize solidarity among group members with "different" cultural backgrounds. The assumptions inherent to those binaries are further integrated within the supposed "culturally responsive" educational practices. In contrast to this universalized version of culture, parental involvement is a symbolic representation of race, gender, and class that is only possibly explicated within the very specific circumstance and interaction. All efforts to develop the "culturally responsive" educational practice runs the risk of "failure" context, unless parental involvement discourse encompasses the multiplicities of culture within a specific sociopolitical context. 


\section{Confronting difficult knowledge}

Real listening in communication is a "painful" process-a process of rethinking assumptions, values, and power operations behind policy decisions. Real listening provokes enduring intellectual and psychological challenges. Pitt and Britzman (2003) differentiate "lovely knowledge" and "difficult knowledge" when confronted with cultural differences. According to Pitt and Britzman, difficult knowledge "is meant to signify both representations of social traumas in curriculum and the individual's encounters with them in pedagogy" (2003, 755). They contrast difficult knowledge with lovely knowledge — knowledge that confirms one's existing beliefs in pedagogy, research, and theories. The authors postulate that the universalized definition of proper parental involvement generates another hegemonic practice that affirms the mainstream teachers' lovely knowledge to define efficient communication for resolving conflicts.

Educators should dismantle lovely knowledge by revisiting the stereotyped understanding of Korean culture. Confronting difficult knowledge requires educators to revisit their existing beliefs about effective communication, or best parental involvement. Furthermore, it is crucial to debunk any stereotypical images of Korean children and their parents related to respecting teachers, perpetual foreigner syndrome, and critical model minority perspectives. Racial and ethnic identity is the shifting signifier, and danger exists when universalized understanding is falsely applied to the racial/ethnic group (Hall, 1997). Teachers need to be more open to reviewing historical, political, and cultural contexts that generate a set of social norms for reiterating in daily practices with ethnic groups. This suggestion for difficult knowledge is an invitation to revisit the assumptions in critical Asian theory. 
In her article, Why doesn't this feel empowering? Working through the repressive myths of critical pedagogy, Ellsworth (1989) argues that critical theory reproduces normalized understandings about empowerment or making one's voice heard. This practice in education does not actually emancipate people who are suffering from institutionalized oppression. Rather, the mantra of empowerment provides another version of hegemony with the use of "should" that is imposed by Eurocentric, patriarchal, and market-driven social ideologies. She argues for different approaches to cultural differences and oppression by acknowledging unknown variables about the Other and its discursive construction with the nexus of power-knowledge. This inquiry is an extension of Ellsworth's invitation to rethink Korean-ness, followed by rethinking Korean parental involvement. In dealing with and confronting the cultural tensions explicated in the previous section, it is crucial to review current assumptions regarding "adequate" parental involvement from multiple angles.

Political actions from Korean parents are imperative to making their voices heard. Strategic provisionality provides the possibility to explicate "Korean-ness" differently: namely, a constant refusal of a ready-made Korean-ness by situating the discursive identity constructions within a very specific sociopolitical, economic, and cultural context. We have refused to introduce Korean culture with the monolithic version of "respecting" teachers and the biopolitics involved with English language. This new approach to cultural difference recognizes the danger of normalizing and standardizing cultural groups. In future research, we propose a further investigation concerning the ways in which Korean culture is constructed within specific sociopolitical contexts. We argue for a political and intellectual project to examine cultural differences in-the-making by minimizing the neglect of the multiplicity of "Korean" parental involvement. 


\section{Implications}

We have problematized how the discourses on US ethnic/racial studies, concerning nonEurocentric parental involvement in particular, are based on "discovering" collective ethnic/racial identity. The main goal of the mainstream ethnic/racial studies aims to close the cultural gaps between "different" ethnic/racial groups. A different approach to ethnoepistemology extends research methodologies by challenging a monolithic version of Korean identity and its representation. Excavating a universalized, seamless version of "culturally responsive" parental involvement normalizes Korean culture and ostracizes "other" Koreans who do not follow a set of cultural norms. Inquiry in ethnic/racial studies should embrace directions that allow for studying the ways in which identities are discursively constructed in specific sociopolitical contexts. Most notably, in the context of parental involvement, we suggest transitioning inquiry in ethnic/racial studies from the discovery of collective identity, to the investigation of historical context in which identity is discursively constructed.

Research on ethnic/racial studies predominantly focuses on interrogating what cultural differences exist between us and them. This dichotomous explication of cultural difference rarely contributes to promoting equity and diversity, but perpetuates stereotypical images about selfother (Santoro 2009). Rather, a critical approach to racial/ethnic studies may include studying the ways in which the notions of "difference" are discursively and politically constructed.

Furthermore, as Butler's strategic provisionality implies, multicultural educators investigate what kinds of social norms construct ethnic/racial identities, and thus examine the open-ended meanings of cultural identities. We propose strategic provisionality to be a critical, political, and intellectual engagement, and ultimately endeavor to recognize that the multiplicities of student 
identities cannot be standardized using the White-Korean dichotomy. A permanent openness towards self and other purports to acknowledge all people as recognizable human beings by not excluding the marginalized person in any given "oppressed" community. The identity label given to "Korean" students and "Korean" families should be strategic, yet provisional, while recognizing the problems embedded within this sign (Butler 1993). Such political actions would minimize the perpetuation of hegemonic practices in racial/ethnic studies, regardless of good intentions to politically emancipate "the oppressed."

\section{References}

Bang, Y. 2009. "Rethinking family involvement: Korean American family involvement in a public kindergarten.” Unpublished Dissertation, Teachers College, Columbia University.

Bourdieu, P., and J. Passeron. 1977/2015. Reproduction in Education, Society and Culture. $2^{\text {nd }}$ ed. Translated and edited by R. Nice. Thousand Oaks, CA: Sage.

Butler, J. 1993. "Imitation and Gender Insubordination.” In The Lesbian and Gay Studies Reader, edited by H. Abelove, M. A. Barale and D. M. Halperin, 307-320. New York: Routledge.

Butler, J. 2003. “Transformative Encounters.” In Women \& Social transformation, edited by E. Beck-Gernsheim, J. Butler and L. Puigvert, 81-98. New York: Peter Lang.

Chae, H. S. 2004. “Talking Back to the Asian Model Minority Discourse: Korean-origin Youth Experiences in High School.” Journal of Intercultural Studies 25 (1): 59-73.

Chang, R. S. 1993. "Toward an Asian American Legal Scholarship: Critical Race Theory, Poststructuralism, and Narrative Space.” California Law Review 81 (5): 1241-1323.

Chen, K. 2010. Asia as Method: Toward Deimperialization. Durham: Duke University Press. 
Coloma, R. S. 2006. "Disorienting Race and Education: Changing Paradigms on the Schooling of Asian Americans and Pacific Islanders.” Race, Ethnicity and Education 9 (1): 1-15.

Cummins, J. 2009. "Pedagogies of Choice: Challenging Coercive Relations of Power in Classrooms and Communities." International Journal of Bilingual Education and Bilingualism 12 (3): 261-271.

Delgado-Gaitan, C. 1991. "Involving Parents in the School: A Process of Empowerment." American Journal of Education 100: 20-46.

Ellsworth, E. 1989. “Why Doesn't This Feel Empowering? Working through the Repressive Myths of Critical Pedagogy." Harvard Educational Review 59 (3): 297-324.

Foucault, M. 1976. The Archaeology of Knowledge. Translated by A. M. S. Smith. New York: Harper \& Row.

Foucault, M. 1977. Discipline and Punish: The Birth of the Prison. Translated by A. Sheridan. New York: Vintage Books.

Foucault, M. 1980. Power/knowledge: Selected Interviews and Other Writings, 1972-1977. Translated by C. Gordon, L. Marshall, J. Mepham, and K. Soper. New York: Pantheon Books.

Glaser, B. G., and Strauss, A. L. 1999. The discovery of grounded theory: Strategies for qualitative research. New York: Aldine de Gruyter.

Hall, S. 1997. "Race, the floating signifier.” Media Education Foundation. Accessed 1 November 2015. https://www.mediaed.org/assets/products/407/transcript 407.pdf Jabal, E., and Riviere, D. 2007. "Student Identities and/in Schooling: Subjection and Adolescent Performativity." Discourse: Studies in the Cultural Politics of Education 28 (2): 197-217. 
Jackson, A. Y. and Mazzei, L. A. 2013. "Plugging One Text into Another: Thinking with Theory in Qualitative Research.” Qualitative Inquiry 19 (4): 261-274.

Kim, A., and Yeh, C. J. 2002. "Stereotypes of Asian American Children and Youth in Schools." Eric Digest: New York. ERIC Clearinghouse on Urban Education.

Kim, Y., Moon, S., and Joo, J. 2013. "Elusive Images of the Other: A Postcolonial Analysis of South Korean World History Textbooks.” Educational Studies 49 (3): 213-246.

Koh, M., Shin, S., and Reeves, K. 2015. "Voices of Culturally and Linguistically Diverse Parents: The Case of Korean-American Parents." Multicultural Learning and Teaching 19 (1): 7-30.

Kumashiro, K. K. 2006. “Afterword: Toward an Anti-oppressive Theory of Asian Americans and Pacific Islanders in Education." Race, Ethnicity and Education 9 (1): 129-135.

Kwon, K., Suh, Y., Bang, Y., Jung, J., and Moon, S. (2010). “The Note of Discord: Examining Educational Perspectives between Teachers and Korean Parents. Teaching and Teacher Education, 26(3): 497-506.

Lazar, A,. and Slostad, F. 1999. "How to Overcome Obstacles to Parent-teacher Partnership." The Clearing House 72 (4): 206-210.

Lee, G. and Manning, M. L. 2001. "Treat Asian Parents and Families Right.” The Education Digest 67 (4): $40-45$.

Lee, S. 2005. "Selective Parent Participation: Structural and Cultural Factors that Influence School Participation among Korean Parents." Equity \& Excellence in Education 38 (4): 299-308.

Lee, S. J. 2006. “Additional Complexities: Social Class, Ethnicity, Generation, and Gender in Asian American Student Experiences." Race, Ethnicity and Education 9(1): 17-28. 
Liebkind, K., Jasinskaja-Lahti, I. and Solheim, E. 2004. “Cultural Identity, Perceived Discrimination, and Parental Support as Determinants of Immigrants' School Adjustment: Vietnamese Youth in Finland." Journal of Adolescent Research, 19 (6), 635-656.

Lim, M. 2012. “Unpacking Parent Involvement: Korean American Parents' Collective Networking." School Community Journal 22 (1): 89-109.

McClelland, J., and Chen, C. 1997. "Standing Up for a Song at School: Experiences of a Mexican Immigrant Mother.” Hispanic Journal of Behavioral Sciences 19 (3): 281-300.

Miller, J. L. 2005. Sounds of Silence Breaking: Women, Autobiography, Curriculum. New York: Peter Lang.

Moon, S. 2011a. “Autobiographical Interrogations of Multicultural Education: Complicating Conversations in Curriculum Studies." Unpublished Dissertation, Teachers College, Columbia University.

Moon, S. 2011b. Rethinking Culturally Responsive Teaching for New (Im)possibilities of Multicultural Curriculum Studies and Policy. Multicultural Education Review, 3(2): 69102.

Ng, J. C., S. S. Lee, and Y. K. Pak. 2007. "Chapter 4: Contesting the Model Minority and Perpetual Foreigner Stereotypes: A Critical Review of Literature on Asian Americans in Education." Review of Research in Education 31 (1): 95-130. doi:10.3102/0091732X06298015.

Olivos, E. 2006. The power of Parents. New York: Peter Lang.

Orozco, G. 2008. "Understanding the Culture of Low-income Immigrant Latino parents: Key to Involvement.” The School Community Journal 18 (1): 21-37. 
Palacios, L. C. 2014. "Racialized and Gendered Necropower in Canadian News and Legal Discourse.” Feminist Formations 26 (1): 1-26. doi:10.1353/ff.2014.0001.

Pinar, W. F., Reynolds, W. M., Slattery, P., and Taubman, P. M. 1995. Understanding Curriculum: An Introduction to the Study of Historical and Contemporary Curriculum Discourses. New York: Peter Lang.

Pitt, A., and Britzman, D. 2003. "Speculations on Qualities of Difficult Knowledge in Teaching and Learning: An Experiment in Psychoanalytic Research.” International Journal of Qualitative Studies in Education, 16: 755 - 776.

Poon, O. A., Squire, D., Kodama, C., Byrd, A., Chan, J., Manzano, L., Furr, S., and Bishundat, D. 2015. "A Critical Review of the Model Minority Myth in Selected Literature on Asian Americans and Pacific Islanders in Higher Education.” Review of Educational Research. http://rer.sagepub.com/content/early/2015/10/26/0034654315612205 (accessed October 4, 2016).

Santoro, N. 2009. “Teaching in culturally diverse contexts: What knowledge about 'self' and 'others' do teachers need? Journal of Education for Teaching 35: 33-45. Retrieved from http://doi.org/10.1080/02607470802587111.

Sleeter, C.E. 2008. "Preparing White Teachers for Diverse Students.” In Handbook of Research on Teacher Education: Ensuring Questions in Changing contexts. $3^{\text {rd }}$ ed., edited by Mc.Cochran-Smith, S. Feiman-Nemser, D.J. McIntyre, and K.E. Demers, 559-582. New York: Routledge.

Sohn, S. and Wang, X. C. 2006. “Immigrant Parents' Involvement in American Schools: Perspectives from Korean Mothers.” Early Childhood Education Journal 34 (2): $125-$ 132. 
Souto-Manning, M. 2006. “A Latina Teacher's Journal: Reflections on Language, Culture, Literacy and Discourse Practices." Journal of Latinos \& Education 5 (4): 293-304.

Spivak, G. C. 1988. “Can the Subaltern Speak?” In The Post-colonial Studies Reader, edited by C. Nelso, and L. Grossbrg, 66-111. Urbana, IL: University of Illinois Press.

Spivak, G. C. 1989. “In a Word: Interview. (E. Rooney, Interviewer).” Differences 1, 124-156.

Spivak, G. C. 1998. In Other Worlds. New York: Routledge.

Turney, K., and Kao, G. 2009. "Barriers to School Involvement: Are Immigrant Parents Disadvantaged?" The Journal of Educational Research 102 (4): 257-271.

Valenzuela, A. 1999. Subtractive Schooling: U.S.-Mexican Youth and the Politics of Caring. Albany, NY: State University of New York Press.

Wu, F. H. 2001. Asian Americans and the Perpetual Foreigner Syndrome. New York: Basic Books. 